\title{
Logística y cadenas de abaste- cimiento motor para el crecimiento
}

Docente Tecnología Logística, UNIMINUTO

La globalización y nuevas tendencias en los mercados obligan actualmente, a empresarios y Estado, a buscar alternativas que les permitan mantenerse y crecer a corto, mediano y largo plazo. Dentro de las muchas alternativas que aparecen para hacer realidad este supuesto encontramos a la logística y las cadenas de abastecimiento como herramientas que involucran todas las características necesarias, para lograr dicho objetivo. Resaltando la importancia de estas para todos los actores dentro del entorno económico mundial, reconociendo su influencia en el desarrollo y crecimiento de las economías asiáticas. Por lo anterior, el articulo a continuación describe cómo la logística y las cadenas de abastecimiento pueden lograr este objetivo con el uso de la inventiva y conocimiento de los expertos en el tema.

\section{¿Qué es logística?}

Es el proceso de planear, implementar y controlar eficientemente el flujo de costos y de almacenamiento de: materias primas, inventarios en proceso, producto terminado e información relacionada desde un punto de origen hasta el punto de consumo, con el propósito de cumplir con los requerimientos del cliente?.

\section{¿Qué es cadena de abastecimiento?}

La gestión de la cadena de abastecimiento (SCM - Supply Chain Management) es el término utilizado para puntualizar el conjunto de procesos de producción y logística cuyo propósito final es la entrega de un producto o servicio a un cliente. Esto quiere decir, que la cadena de abastecimiento incluye todas las acciones asociadas desde la producción de materias primas para obtener un producto terminado o servicio, hasta su distribución y entrega a un cliente final. 
La cadena de abastecimiento se extiende desde el cliente de tu cliente hasta el proveedor de tu proveedor y la logística apoya este proceso en cada eslabón de la cadena.

Para ilustrar esta parte, tomemos como ejemplo una compañía textil que elabore camisas para hombres. Partiendo del supuesto del éxito de antemano, pues somos especialistas en el diseño, corte y confección de camisas, conocemos las tendencias de la moda y hemos rentado una tecnología de punta equipada para hacer una camisa en sólo 60 minutos. ¿Hace falta pensar en algo más? La cadena de abastecimiento. Tener disponible la materia prima para la elaboración del producto es decisivo y es lamentable estar al tanto una vez puesto en marcha el proyecto que la disponibilidad de textiles para fabricar nuestras camisas demora aproximadamente 5 semanas de transformación, desde el pedido a nuestro proveedor, más posiblemente otras 9 semanas de transporte. $Y$ eso sin tener en cuenta 3 semanas que demoraremos en ubicar nuestras camisas en distribuidores y almacenes a lo largo y ancho del país. ¿Cómo conseguimos mantener controlados los procesos que implican la manufactura de nuestras camisas? La respuesta está en tener una adecuada gestión de la cadena de abastecimiento. (Figura 1).

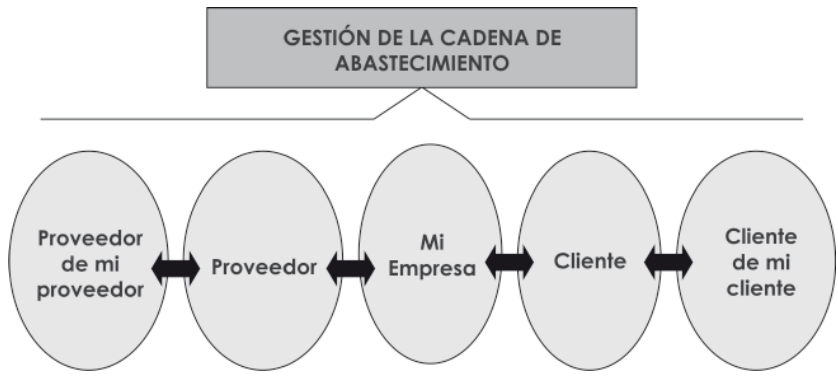

Figura 1. Estructura de la cadena de abastecimiento².

El mejoramiento en las cadenas de abastecimiento da como resultado soluciones que impulsan a la organización a la cúspide respecto de las otras de su misma categoría, el camino hacia una posición de vanguardia requiere enfoque, dedicación, creatividad y trabajo arduo; una compañía que crea que va a saltar hasta al nivel mas alto, en un periodo muy corto o sin un trabajo enfocado, descubrirá que este esfuerzo es infructuoso y por el contrario le ocasionará problemas. Para lograr el máximo se debe desarrollar una estrategia para un desplazamiento rápido a través de la cadena de abastecimiento, al interior y exterior de la organización.

\begin{tabular}{|c|c|c|c|c|}
\hline & INTERNO & & EXTERNO & \\
\hline & $\begin{array}{l}\text { Abasteci- } \\
\text { miento y } \\
\text { logística I }\end{array}$ & $\begin{array}{l}\text { Excelencia } \\
\text { Interna II }\end{array}$ & $\begin{array}{l}\text { Construcción } \\
\text { de la Red III }\end{array}$ & $\begin{array}{l}\text { Liderazgo de } \\
\text { la Industria IV }\end{array}$ \\
\hline Impulsor & $\begin{array}{l}\text { Respon- } \\
\text { sable de } \\
\text { abaste- } \\
\text { cimiento } \\
\text { (bajo } \\
\text { presión) }\end{array}$ & $\begin{array}{l}\text { Director de } \\
\text { información } \\
\text { / líder de la } \\
\text { cadena de } \\
\text { abasteci- } \\
\text { miento }\end{array}$ & $\begin{array}{l}\text { Lideres de la } \\
\text { unidad de } \\
\text { negocios }\end{array}$ & $\begin{array}{l}\text { Equipo de } \\
\text { administra- } \\
\text { ción }\end{array}$ \\
\hline Beneficios & $\begin{array}{l}\text { Ahorros } \\
\text { influidos }\end{array}$ & $\begin{array}{l}\text { Mejora- } \\
\text { mientos con } \\
\text { prioridad a } \\
\text { lo largo de } \\
\text { la red }\end{array}$ & $\begin{array}{l}\text { Desempeño } \\
\text { del mejor } \\
\text { socio }\end{array}$ & $\begin{array}{l}\text { Ventaja } \\
\text { de la red } \\
\text { ingresos } \\
\text { rentables }\end{array}$ \\
\hline Enfoque & $\begin{array}{l}\text { Inventario, } \\
\text { logística, } \\
\text { flete, surtido } \\
\text { de pedidos }\end{array}$ & $\begin{array}{l}\text { Rediseño } \\
\text { del sistema } \\
\text { mejora del } \\
\text { sistema }\end{array}$ & $\begin{array}{l}\text { Pronostico, } \\
\text { planificación, } \\
\text { servicio al } \\
\text { cliente, inter- } \\
\text { empresa }\end{array}$ & $\begin{array}{l}\text { Consumidor, } \\
\text { red }\end{array}$ \\
\hline $\begin{array}{l}\text { Herra- } \\
\text { mientas }\end{array}$ & $\begin{array}{l}\text { Formación } \\
\text { de equipos, } \\
\text { excelencia } \\
\text { funcional }\end{array}$ & $\begin{array}{l}\text { Evaluacio- } \\
\text { nes com- } \\
\text { parativas } \\
\text { (benchmar- } \\
\text { king), mejor } \\
\text { practica, } \\
\text { costeo ba- } \\
\text { sado en la } \\
\text { actividad }\end{array}$ & $\begin{array}{l}\text { Métrica, } \\
\text { explotación } \\
\text { de la base } \\
\text { de datos, } \\
\text { comercio } \\
\text { electrónico }\end{array}$ & $\begin{array}{l}\text { Red interna, } \\
\text { Internet, } \\
\text { sistemas de } \\
\text { información } \\
\text { virtual }\end{array}$ \\
\hline $\begin{array}{l}\text { Área de } \\
\text { Acción }\end{array}$ & $\begin{array}{l}\text { Organi- } \\
\text { zación } \\
\text { del nivel } \\
\text { intermedio }\end{array}$ & $\begin{array}{l}\text { Niveles ex- } \\
\text { pandidos }\end{array}$ & $\begin{array}{l}\text { Organización } \\
\text { total }\end{array}$ & $\begin{array}{l}\text { Empresa } \\
\text { completa }\end{array}$ \\
\hline Gobierno & $\begin{array}{l}\text { Información } \\
\text { de costos, } \\
\text { financia- } \\
\text { miento del } \\
\text { éxito }\end{array}$ & $\begin{array}{l}\text { Conversión } \\
\text { (mapping) } \\
\text { de procesos }\end{array}$ & $\begin{array}{l}\text { Modelos } \\
\text { de costo } \\
\text { avanzados, } \\
\text { procesos de } \\
\text { diferencia- } \\
\text { ción }\end{array}$ & $\begin{array}{l}\text { Vinculación } \\
\text { oferta - de- } \\
\text { manda }\end{array}$ \\
\hline Modelo & Ninguno & $\begin{array}{l}\text { Cadena de } \\
\text { abasteci- } \\
\text { miento -in- } \\
\text { tra empresa }\end{array}$ & $\begin{array}{l}\text { Ínter } \\
\text { empresa }\end{array}$ & $\begin{array}{l}\text { Mercado } \\
\text { global }\end{array}$ \\
\hline Alianzas & $\begin{array}{l}\text { Consoli- } \\
\text { dación de } \\
\text { proveedo- } \\
\text { res }\end{array}$ & Mejor socio & $\begin{array}{l}\text { Alianzas } \\
\text { formales }\end{array}$ & $\begin{array}{l}\text { Empresas } \\
\text { conjuntas }\end{array}$ \\
\hline $\begin{array}{l}\text { Capacita- } \\
\text { ción }\end{array}$ & Equipo & Liderazgo & Asociación & $\begin{array}{l}\text { Procesa- } \\
\text { miento de } \\
\text { la red }\end{array}$ \\
\hline
\end{tabular}

El objetivo principal es obtener una ganancia sustancial en la contención de los costos, organizar un esfuerzo por el mejoramiento concertado o reestructurar un proceso que disminuya drásticamente los costos. Las empresas que ya han comenzado el desarrollo de estos procesos, identifican que la mayor parte de los miembros en función de compras en corporaciones grandes están familiarizados con las presiones impuestas sobre las concesiones forzadas de los proveedores durante las primeras fases de las mejoras a las cadenas de abastecimiento y actividades de asociación de empresas, progresan hábil-

2. ESPACIOPYME S.A. Supply Chain Management. Monográfico patrocinado por IBM Junio 2003.

3. Poirier, Charles C. Administración de Cadenas de Aprovisionamiento. México: Oxford, 2001. P28. 
mente reduciendo costos influyendo en los proveedores con su volumen y posición de compras. Pero, se debe prestar especial atención a los proveedores que aprueban concesiones de precio a cambio de posiciones de volumen, el resultado en esta operación no siempre es el mejor al caber la posibilidad de una disminución en el servicio y un desempeño al aprovisionamiento de menor calidad. Lo mejor es establecer con el proveedor hasta qué punto este tipo de concesiones afectan la operación en ambas partes.

\section{¿Cómo se obtienen beneficios?}

Los primeros beneficios se obtienen por medio de los esfuerzos por mejorar la cadena de abastecimiento, trabajando en proyectos por parte de equipos que reduzcan los costos de compra, inventarios, logística y de fletes. Estos esfuerzos deben incluir un intercambio de volúmenes de ventas (el apalancamiento), por algún tipo de ahorro (el beneficio). Sin embargo, deben extremarse las precauciones ya que la experiencia ha demostrado que algunos de los ahorros en esta primera parte son ficticios. Si en esta etapa estamos estudiando la posibilidad de tercerizar o ceder alguna actividad debemo evaluar, minuciosamente, el costo de la misma realizada por nosotros y cuánto nos vale subcontratarla porque, en ocasiones, se puede incrementar la operación.

Cuando se trabaja en proyectos específicos de la cadena de abastecimiento tales como logística, fletes, y surtido de pedidos se deben adoptar precauciones adicionales para validar los supuestos resultados después de haber tocado el tema de compras, por la importancia que representan estos grandes sectores, su orientación apuntará a dos proposiciones: se rediseña, reestructura el proceso para volverse más eficiente o se busca una compañía externa a la que pueda confiársele dicho proceso (subcontratación), de manera que la empresa pueda centrarse en actividades primordiales.

Los fletes son un área particularmente fértil. Aquí depende de la habilidad de las compañías para sobresalir en este proceso, mientras otras son débiles e inmediatamente mostrarán una inclinación precoz hacia la búsqueda de subcontrataciones y la distribución de pedidos resultará ser un reto porque la mayoría de los problemas, en esta área, se encuentran al interior de las empresas. Una completa falta de disciplina es la mayor fuente de los problemas, lo cual evidenciará errores mucho más allá de cualquier límite de manufactura. Un error que se debe evitar, al encontrar soluciones, es eliminar trabajadores en el proceso porque los mismos pueden entorpecer la marcha a lo largo de la cadena. Los ahorros en la fuerza de trabajo muy seguramente aparecerán a medida que se eliminen los errores, se simplifiquen los procesos y se creen e implementen sistemas automatizados. Es aconsejable la reubicación de los trabajadores al interior de la organización o asegurarles su traslado a otro actor dentro de la cadena. Las empresas buscarán realizar sus entregas a través de centros de distribución regionales estratégicamente colocados. De acuerdo con esto, se debe analizar el procesamiento de ventas, desempeño del crédito, los costos de transporte, de reabastecimiento de inventarios y el servicio al cliente, con el fin de identificar numerosas oportunidades de mejoramiento.

Es necesario elaborar o examinar minuciosamente el diagrama de flujo para identificar los pasos que no contribuyan en nada a la satisfacción de las necesidades del cliente. La reducción del tiempo del ciclo se convierte en un factor guía, lo mismo que el potencial para eliminar inventarios no necesarios para mantener la tasa de reaprovisionamiento y los tipos de entrega dentro de los estándares aceptables. Cada uno de ellos debe analizarse de manera intensa y ser desarrollados, modificados en favor de sistemas más simples fluidos y eficaces.

En una primera etapa, se sugirió la administración de cadenas de abastecimiento enfocadas, por lo general, en técnicas para formar equipos; se trabaja en funciones tales como compras, logística y fletes, por ser elecciones obvias los equipos utilizan el desarrollo de guiones; es decir, cuadros de trabajo, flujograma de procesos, toma de decisiones, y otros instrumentos. Para incentivar al grupo, las áreas de acción que se trabajan dentro de la organización son gerentes y directivos funcionales que adoptan el peso y la responsabilidad de implantar los nuevos procesos. La orientación de cualquier dato financiero o costo a los que se tenga acceso. El interés se debe enfocar, ahora, en los sistemas de manufactura y entrega. Se deben explorar áreas, que normalmente no estarían bajo la atención del departamento de compras pero que todavía comprenden costos significativos.

\section{¿Cómo crear su propio modelo?}

De acuerdo con sus características, necesidades y afinidad con sus socios, los actores crean su propio método, con base en el sector económico al cual pertenecen, y los objetivos que se fijen entre sí para lograr niveles de competitividad aceptables. Apoyándose en técnicas de formación de equipos prescritos de manera general, es aconsejable tener sesiones de lluvias de ideas; tomar en cuenta la opinión de los subalternos, pues ellos viven el día a día de la opera- 
ción; realizar un análisis a la información anterior para evaluar las oportunidades de mejoramiento basados en la estadística; desarrollar una lista de oportunidades en secuencia prioritaria de manera que puedan seleccionarse las iniciativas de mejor potencial y se formen los equipos de implantación. Los programas de generación de ideas deben comenzar con proveedores clave para identificar dónde se pueden generar ahorros.

La capacitación es un factor clave y se debe orientar principalmente al desarrollo de capacidades para la formación de equipos, la identificación de problemas y el análisis de causas fundamentales y de otros elementos. De un buen trabajo en equipo depende en gran parte el éxito del proceso.

Como es de esperarse los directivos estarán a la expectativa de los resultados, por las mejoras realizadas. Y gracias a estos esfuerzos en una primera etapa, sin exagerar pero siendo lo suficientemente objetivos para la mayor parte de las empresas, se pueden alcanzar un mejoramiento de $10 \%$ al $15 \%$ en los costos de compras. Los inventarios se reducen de $10 \%$ a $20 \%$ y los costos de logística de $5 \%$ al $10 \%$. Es posible un aumento de costos en los empleados de oficina en la medida que se adicione personal exterior para poner en su lugar los sistemas, lo cual sería temporal. Igual el aprendizaje tiene que extenderse, mientras el proceso se valida y se encuentran debilidades.

\section{Descubra nuevas oportunidades}

Los cambios recomendados son rentables y su implantación conduce a ahorros documentados que pueden usarse para financiar esfuerzos futuros, el proceso es autocosteable, la inversión si es necesaria sería mínima y sólo en la puesta en marcha del proceso. La vinculación de la oferta y la demanda a lo largo de una red completa es algo que será evasivo para los actores pero, obligatoriamente, se deben buscar los mecanismos para trabajar con base en estos controlando los excesos. Consideremos algunas de las dificultades más comunes en la puesta en marcha de este tipo de proyecto, donde las mismas nos arrojan oportunidades de progreso frente a nuestros competidores:

1. Resistencia natural al cambio en algunas organizaciones, a menudo exacerbada por una cultura del "no se inventó aqui".

2. Rehusarse a compartir las ganancias del esfuerzo de mejoramiento.

3. Los recursos insuficientes retrasan el progreso.

4. La falta de compromiso por parte de los directivos y ejecutivos.

5. Sólo cuando existe un énfasis visible y continuo en el mejoramiento del proceso hacia los mas altos niveles, el progreso continúa.

6. Pasar por alto pronósticos pobres inhibe el grado de mejoramiento que puede alcanzarse. Obtener mejor información para un sistema de aprovisionamiento, respecto a cuánta demanda real habrá durante un marco de tiempo específico.

7. La tendencia a aplicar la tecnología reactiva da como resultado una pobre alineación de la tecnología de información.

8. La falta de confianza hace que los posibles aliados, en la cadena de aprovisionamiento, repriman su pericia e inhiban la cooperación.

De lo anterior se sugiere evaluar dónde estamos cometiendo el error para repararlo; cambiar la perspectiva frente al obstáculo y observar detenidamente dónde está la oportunidad.

De los esfuerzos realizados la cadena de abastecimiento aumentará en importancia, desde una colección de centros de costos que trabajan de manera independiente y necesitan un mejoramiento constante, hasta un recurso estratégico que puede permitir la ventaja competitiva.

El objetivo principal es lograr un mejoramiento de la cadena de abastecimiento, descubriendo el valor de contemplar el negocio de manera holística, desde el suministro inicial hasta el consumo final, lo que tendrá que arrojar beneficios que pueden ganarse a lo largo de todo el sistema. Esto se podrá lograr con la utilización de mapas de procesos, la formación de equipos, el rediseño de procesos y lo más importante el compromiso de quienes dirijan el proceso. Siempre resaltando que los mejores resultados se reflejaran en el área de compras, transporte, inventario y almacenamiento.

Es muy importante en la implementación de este proceso no concentrar la división de los ahorros en los directivos y ejecutivos de la compañía sino crear recompensas también para proveedores, empleados, distribuidores y demás individuos involucrados, que han permitido este tipo de mejoramiento. Con lo anterior se motivará a las personas involucradas a colaborar en la búsqueda de mas fuentes de ahorro y lo más importante: la continuidad en el tiempo del proceso. 